\title{
Prevalence of urogenital, anal, and pharyngeal infections with Chlamydia trachomatis, Neisseria gonorrhoeae, and Mycoplasma genitalium: a cross-sectional study in Reunion island
}

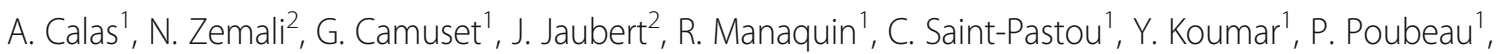 \\ P. Gerardin ${ }^{3}$ and A. Bertolotti ${ }^{1,3^{*}}$ (D)
}

\begin{abstract}
Background: Recommendations for sexually transmitted infection (STI) screening vary significantly across countries. This study evaluated the prevalence of urogenital and extragenital infections with Chlamydia trachomatis (CT), Neisseria gonorrhoeae (NG), and Mycoplasma genitalium (MG) in patients visiting a French STI clinic in the Indian Ocean region to determine whether current STI screening practices should be updated.

Methods: This cross-sectional study examined all patients who visited the STI clinic between 2014 and 2015. Triplex polymerase chain reaction screening for $C T, N G$, and $M G$ was performed on urine, vaginal, pharyngeal, and anal specimens (FTD Urethritis Basic Kit, Fast Track Diagnostics, Luxembourg).

Results: Of the 851 patients enrolled in the study, 367 were women $(367 / 851,43.2 \%)$ and 484 were men (484/851, 56.0\%). Overall, 826 urogenital specimens (826/851, 97.1\%), 606 pharyngeal specimens (606/851, 71.2\%), and 127 anal specimens $(127 / 851,14.9 \%)$ were taken from enrolled patients. The prevalence of urogenital CT and MG was high in women $\leq 25$ years $(19 / 186,10.21 \% ; 5 / 186,2.69 \%)$ and in men who have sex with women $\leq 30$ years $(16 / 212$, 7.54\%; 5/212, 2.36\%). Among patients with urogenital CT infection, 13.7\% (7/51) had urethritis. All patients with urogenital MG infection were asymptomatic. Men who have sex with men had a high prevalence of pharyngeal $\mathrm{CT}$ $(2 / 45,4.44 \%)$ and NG $(3 / 44,6.81 \%)$ and a high prevalence of anal CT $(2 / 27,7.41 \%), N G(2 / 27,7.40 \%)$, and MG $(1 / 27$, 3.70\%). After excluding patients with concomitant urogenital infection, extragenital infections with at least 1 of the 3 pathogens were found in 20 swabs (20/91, 21.9\%) taken from 16 patients (16/81, 19.7\%), all of them asymptomatic.

\footnotetext{
* Correspondence: antoine_bertolotti@yahoo.fr

${ }^{1} \mathrm{CHU}$ Réunion, Service des Maladies Infectieuses - Dermatologie, Saint Pierre, La Réunion, France

${ }^{3}$ Inserm ClC1410, CHU Réunion, Saint Pierre, La Réunion, France

Full list of author information is available at the end of the article
}

(c) The Author(s). 2021 Open Access This article is licensed under a Creative Commons Attribution 4.0 International License, which permits use, sharing, adaptation, distribution and reproduction in any medium or format, as long as you give appropriate credit to the original author(s) and the source, provide a link to the Creative Commons licence, and indicate if changes were made. The images or other third party material in this article are included in the article's Creative Commons licence, unless indicated otherwise in a credit line to the material. If material is not included in the article's Creative Commons licence and your intended use is not permitted by statutory regulation or exceeds the permitted use, you will need to obtain permission directly from the copyright holder. To view a copy of this licence, visit http://creativecommons.org/licenses/by/4.0/ The Creative Commons Public Domain Dedication waiver (http://creativecommons.org/publicdomain/zero/1.0/) applies to the data made available in this article, unless otherwise stated in a credit line to the data. 
(Continued from previous page)

Conclusions: Routine multisite screening for $\mathrm{CT}, \mathrm{NG}$, and $\mathrm{MG}$ should be performed to mitigate the transmission of STIs in high-risk sexually active populations.

Keywords: Sexually transmitted infections, Screening, Chlamydia trachomatis, Neisseria gonorrhoeae, Mycoplasma genitalium, Reunion island

\section{Background}

Sexually transmitted infections (STIs) are a major public health concern, especially since their prevalence is increasing globally [1]. When left untreated, infections with Chlamydia trachomatis (CT), Neisseria gonorrhoeae (NG), and Mycoplasma genitalium (MG) can cause severe long-term complications, including pelvic inflammatory disease, ectopic pregnancy, infertility, chronic pelvic pain, and neurological or cardiovascular diseases [2]. Because infected patients are often asymptomatic, screening for these pathogens presents a major challenge. International STI guidelines [3] strongly encourage annual screening for urogenital CT and NG in men who have sex with men (MSM), sexually active women $\leq 25$ years, at-risk women $>25$ years, and at-risk men who have sex with women (MSW) (risky behaviour being defined here as having new or multiple sex partners, having received a recent STI diagnosis, having sex for money, or having sex while on drugs). Although routine screening for extragenital CT and NG in MSM and at-risk women (defined as women who engage in anal or oral sex) is recommended in some developed countries (i.e. France, Canada, and Australia), STI guidelines published in other countries, both developed and developing, do not make specific recommendations for extragenital infections. Lastly, available recommendations regarding MG infection generally discourage the screening of asymptomatic patients regardless of infection site to prevent the overprescription of azithromycin and the resulting increase in antimicrobial resistance. This is perplexing considering that MG infection is the second most common cause of nongonococcal urethritis [4].

As extragenital infections can occur without concomitant urogenital infection [5], symptom-based urogenital screening alone may cause a large number of STIs to go undetected and untreated. Moreover, this screening approach can generate a false sense of security in asymptomatic patients, which in turn can facilitate the spread of STIs in the population. This is a major issue in lowand middle-income regions like Reunion Island, as these are often home to high-risk sexually active populations.

This study evaluated the prevalence of urogenital, anal, and pharyngeal infections with CT, NG, and MG in patients visiting an STI clinic in Reunion Island to determine whether STI screening practices should be updated.

\section{Methods}

This monocentric cross-sectional study examined all patients who visited a major STI clinic in Reunion Island between June 2014 and August 2015. All patients were asked to complete an anonymous questionnaire that collected data on age, marital status, level of education, drug use, sexual activity, urogenital symptoms, and extragenital (i.e. pharyngeal or anal) symptoms (Additional file 1). Urine specimens were collected from men, vaginal self-swab specimens from women, and pharyngeal and anal swab specimens from at-risk patients (i.e. men and women who engage in anal and/or oral sex) and MSW volunteers. All specimens were screened by triplex polymerase chain reaction (PCR) for CT, NG, and MG (FTD Urethritis Basic Kit, Fast Track Diagnostics, Luxembourg). Specimens with cycle threshold values $\leq 38$ and exponential amplification curves were considered positive. Patients also underwent serological tests for HIV, HBV, and HCV. Quantitative variables were expressed as means with standard deviation (SD), and prevalence and qualitative variables were expressed as percentages. The $95 \%$ confidence intervals $(95 \% \mathrm{CI})$ of STI prevalence estimates were calculated using adjusted binomial distribution. Statistical analyses were performed using R software (R Core Team 2019, R Foundation for Statistical Computing, Vienna, Austria). A $P$-value $<0.05$ was considered statistically significant.

Oral informed consent was obtained from all participants and written informed consent was obtained from a parent or guardian for participants under 18 years old. The ethical character of oral consent alone for this study on totally anonymous collected data was approved by the Scientific Committee for research of the CHU Réunion. No review by an ethical committee was required (article R1121-1, decree $n^{\circ} 2017-884$ of 9 May 2018 - art.2). The study was registered with the National Institute of Health Data (MR 0912200220) in accordance with French regulations and was conducted using the MR-004 reference methodology of the Commission Nationale Informatique et Libertés (CNIL).

\section{Results}

Over the 14-month period, 851 patients were enrolled in the study, including 367 women $(367 / 851,43.2 \%)$ and 484 men (484/851, 56.0\%). Of these, 796 patients (796/ $851,95.5 \%)$ completed the questionnaire; questionnaires 
were not obtained from the other 55 patients $(55 / 851$, $6.5 \%)$ because they were wrongly administered. No significant difference was observed in STI prevalence between respondents and non-respondents. A total of 53 men $(53 / 484,10.9 \%)$ were MSM. Mean age was 28.95 (14-70, SD 10.61) years. Overall, 826 urogenital specimens (826/851, 97.1\%), 606 pharyngeal specimens (606/ 851, 71.2\%), and 127 anal specimens (127/851, 14.9\%) were taken from the 851 enrolled patients (Fig. 1). A total of 95 specimens $(95 / 1559,6.1 \%)$ taken from 85 patients $(85 / 851,9.9 \%$, mean age 26.31 years, $15-70$, SD 9.84) were positive for at least 1 of the 3 pathogens, including 71 urogenital specimens (71/826, 8.6\%), 16 pharyngeal specimens $(16 / 606,2.6 \%)$, and 8 anal specimens $(8 / 127,6.2 \%)$. Table 1 shows the prevalence of $C T$, NG, and MG in the 3 types of specimen. Three CT-MG co-infections and 7 CT-NG co-infections were found. Pharyngeal and anal infections with concomitant urogenital infection were excluded from the analysis. The overall prevalence of CT in urogenital, pharyngeal, and anal specimens was $6.17 \%(51 / 826), 1.98 \%(12 / 606)$, and $7.87 \%$ (10/127), respectively. The prevalence of NG in urogenital, pharyngeal, and anal specimens was $0.73 \%$ (6/826), $1.48 \%$ (9/606), and 3.15\% (4/127), respectively. The prevalence of MG in urogenital, pharyngeal, and anal specimens was $1.81 \%(15 / 826), 0.33 \%(2 / 606)$, and $2.36 \%(3 / 127)$ respectively.

The prevalence of urogenital CT infection was $10.21 \%$ $(19 / 186,95 \%$ CI $6.26-15.49 \%, p=0.02)$ in women $\leq 25$ years and $7.54 \%(16 / 212$, 95\% CI $4.37-11.97 \%, p=0.05)$ in MSM.

The prevalence of anal CT infection without concomitant urogenital infection was 5.56\% (2/36 95\%CI 0.68-18.66\%, $p=0.7)$ in women $\leq 25$ years and $7.41 \%(2 / 27,95 \%$ CI $0.91-$ $24.29 \%$ ) in MSM. The prevalence of pharyngeal CT infection without concomitant urogenital infection was $2.83 \%$ $(4 / 141,95 \%$ CI $0.78-7.10 \%, p=0.12)$ in women $\leq 25$ years and $4.44 \%(2 / 45$, 95\%CI $0.54-15.15 \%)$ in MSM.

The prevalence of anal NG infection without concomitant urogenital infection was $7.40 \%(2 / 27,95 \% \mathrm{CI} 0.91$ -

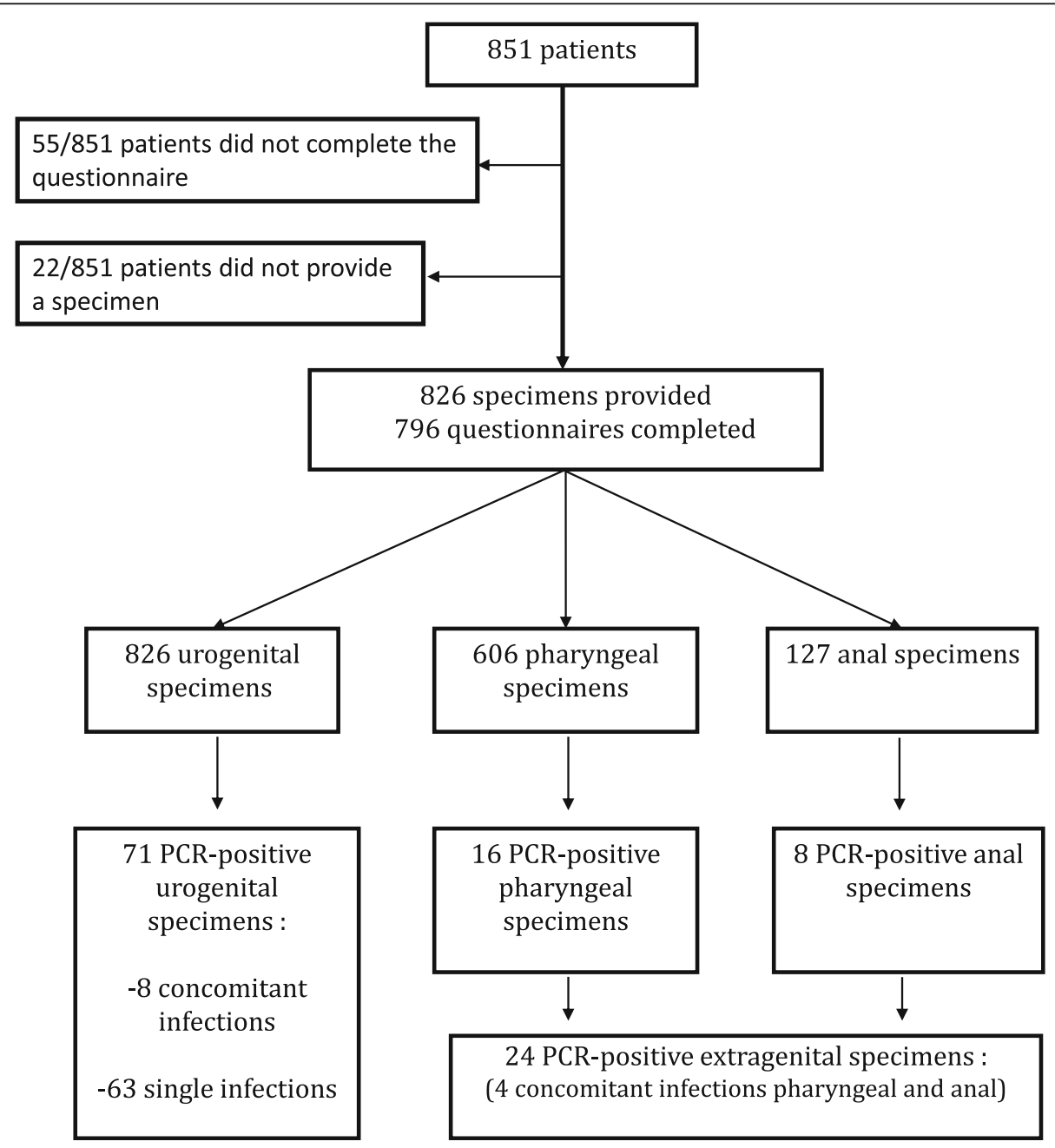

Fig. 1 Flow chart of enrolled patients 
Table 1 Prevalence of Chlamydia trachomatis, Neisseria gonorrhea, Mycoplasma genitalium in the 3 types of specimen (Reunion Island, 2014-2015)

\begin{tabular}{|c|c|c|c|c|c|c|c|c|c|}
\hline & \multicolumn{3}{|c|}{ Urogenital specimen } & \multicolumn{3}{|c|}{ Pharyngeal specimen $^{a}$} & \multicolumn{3}{|c|}{ Anal specimen ${ }^{a}$} \\
\hline & $\mathrm{n} / \mathrm{N}$ & $P$-value ${ }^{\mathrm{e}}$ & Prevalence $\left(95 \% \mathrm{Cl}^{d}\right)$ & $\mathrm{n} / \mathrm{N}$ & $P$-value ${ }^{\mathrm{e}}$ & Prevalence $\left(95 \mathrm{Cl} \%^{d}\right)$ & $\mathrm{n} / \mathrm{N}$ & $P$-value ${ }^{\mathrm{e}}$ & Prevalence $\left(95 \mathrm{Cl}^{\mathrm{d}}{ }^{\mathrm{d}}\right)$ \\
\hline \multicolumn{10}{|c|}{ Chlamydia trachomatis infection } \\
\hline Women $\leq 25 y$ & $19 / 186^{b}$ & 0.02 & $10.21(6.26-15.49)$ & $4 / 141^{f}$ & 0.12 & $2.83(0.78-7.10)$ & $2 / 36^{\mathrm{f}, \mathrm{h}}$ & 0.7 & $5.56(0.68-18.66)$ \\
\hline Women $>25 y$ & $7 / 159^{b}$ & - & $4.40(1.79-8.86)$ & $0 / 134$ & - & $0.00(0.00-2.72)$ & $0 / 49$ & - & $0.00(0.00-7.26)$ \\
\hline MSM & $2 / 53$ & & $3.77(0.46-12.98)$ & $2 / 45^{f}$ & & $4.44(0.54-15.15)$ & $2 / 27^{\text {f,h }}$ & & $7.41(0.91-24.29)$ \\
\hline MSW $\leq 30 y$ & $16 / 212$ & 0.05 & $7.54(4.37-11.97)$ & $1 / 147$ & 0.63 & $0.68(0.02-3.73)$ & $0 / 2$ & & $0.00(0.00-84.19)$ \\
\hline MSW >30y & $4 / 124$ & - & $3.23(0.89-8.05)$ & $0 / 88$ & - & $0.00(0.00-4.11)$ & $0 / 1$ & & $0.00(0.00-97.50)$ \\
\hline Other men ${ }^{c}$ & $2 / 92$ & & $2.17(0.26-7.63)$ & $1 / 47$ & & $2.13(0.05-11.29)$ & $0 / 8$ & & $0.00(0.00-36.94)$ \\
\hline \multicolumn{10}{|c|}{ Neisseria gonorrhea infection } \\
\hline Women $\leq 25 y$ & 2/186 & 0.41 & $1.07(0.13-3.83)$ & $0 / 139$ & 0.5 & $0.00(0.02-2.62)$ & $0 / 38$ & & $0.00(0.00-9.25)$ \\
\hline Women $>25 y$ & $1 / 159$ & - & $0.63(0.01-3.45)$ & $0 / 133$ & & $0.00(0.00-2.74)$ & $0 / 50$ & & $0.00(0.00-7.11)$ \\
\hline MSM & $2 / 53$ & & $3.77(0.46-12.98)$ & $3 / 44^{9}$ & & $6.81(1.43-18.66)$ & $2 / 27^{9}$ & & $7.40(0.91-24.29)$ \\
\hline MSW $\leq 30 y$ & $1 / 212$ & 0.63 & $0.47(0.01-2.60)$ & $1 / 147$ & 0.26 & $0.68(0.02-3.73)$ & $0 / 2$ & & $0.00(0.00-84.19)$ \\
\hline MSW >30y & $0 / 124$ & - & $0.00(0.00-2.93)$ & $2 / 88$ & - & $2.27(0.28-7.97)$ & $0 / 1$ & & $0.00(0.00-97.50)$ \\
\hline Other men ${ }^{c}$ & $0 / 92$ & & $0.00(0.00-3.97)$ & $0 / 47$ & & $0.00(0.00-7.55)$ & $0 / 8$ & & $0.00(0.00-36.94)$ \\
\hline \multicolumn{10}{|c|}{ Mycoplasma genitalium infection } \\
\hline Women $\leq 25 y$ & $5 / 186$ & 0.2 & $2.69(0.88-6.16)$ & $1 / 145$ & 0.5 & $0.72(0.02-4.09)$ & $0 / 39$ & 0.56 & $0.00(0.07-9.03)$ \\
\hline Women $>25 y$ & $2 / 159$ & - & $1.26(0.15-4.47)$ & $1 / 134$ & - & $0.75(0.02-4.12)$ & $1 / 50$ & - & $2.00(0.05-10.65)$ \\
\hline MSM & $1 / 53$ & & $1.89(0.05-10.07)$ & $0 / 45$ & & $0.00(0.00-7.87)$ & $1 / 27$ & & $3.70(0.09-18.97)$ \\
\hline MSW $\leq 30 y$ & $5 / 212$ & 0.1 & $2.36(0.77-5.42)$ & $0 / 147$ & & $0.00(0.00-2.48)$ & $0 / 2$ & & $0.00(0.00-84.19)$ \\
\hline MSW >30y & $0 / 124$ & - & $0.00(0.00-2.93)$ & $0 / 88$ & & $0.00(0.00-4.11)$ & $0 / 1$ & & $0.00(0.00-97.50)$ \\
\hline Other men ${ }^{c}$ & $2 / 92$ & & $2.17(0.26-7.63)$ & $0 / 47$ & & $0.00(0.00-7.55)$ & $0 / 8$ & & $0.00(0.00-36.94)$ \\
\hline
\end{tabular}

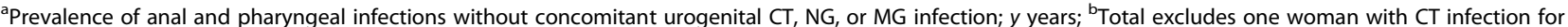
whom age was unknown; MSM men who have sex with men, $M S W$ men who have sex with women; ${ }^{c}$ men who did not share their sexual orientation; $C l$

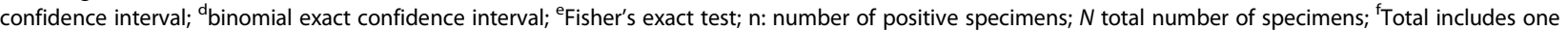
specimen with concomitant pharyngeal and anal infections; ${ }^{9}$ Total includes two patients with concomitant pharyngeal and anal infections; ${ }^{h}$ no anorectitis reported by infected patients

24.29\%) in MSM. The prevalence of pharyngeal NG infection without concomitant urogenital infection was $6.81 \%$ (3/44, 95\%CI 1.43-18.66\%) in MSM.

The prevalence of anal MG infection without concomitant urogenital infection was $2 \%(1 / 50,95 \%$ CI 0.05 , $10.65 \%)$ in women $>25$ years and $3.70 \%(1 / 27,95 \% \mathrm{CI}$ $0.09-18.97 \%)$ in MSM. The prevalence of pharyngeal MG infection without concomitant urogenital infection was $0.72 \%(1 / 145,95 \% \mathrm{CI} 0.02-4.09 \%, p=0.5)$ in women $\leq 25$ years and $0.75 \%(1 / 134,95 \% \mathrm{CI} \quad 0.02-4.12 \%)$ in women $>25$ years.

After excluding patients with concomitant urogenital infection and MSW volunteers, extragenital infections with at least 1 of the 3 pathogens were found in 20 swabs $(20 / 91,21.9 \%)$ taken from 16 patients $(16 / 81$, $19.7 \%$ ), all of them asymptomatic. Among patients with urogenital CT infection, 13.7\% (7/51 had urethritis. Among patients with urogenital NG infection, 16.6\% (1/ 6) had hematuria and $16.6 \%(1 / 6)$ had urethritis. All patients with urogenital MG infection were asymptomatic.

\section{Discussion}

This study evaluated the prevalence of urogenital, anal, and pharyngeal infections with CT, NG, and MG in patients visiting an STI clinic in Reunion Island to determine whether current STI screening practices should be updated. A high prevalence of urogenital CT and MG was found in both women $\leq 25$ years $(19 / 186,10.21 \%$; $2.69 \%)$ and MSW $\leq 30$ years (16/212, 7.54\%; $2.36 \%$ ). Moreover, MSM were found to have a high prevalence of pharyngeal CT $(2 / 45,4.44 \%)$ and NG $(3 / 44,6.81 \%)$ and a high prevalence of anal CT (2/27, 7.41\%), NG (2/ $27,7.40 \%)$, and MG $(1 / 27,3.70 \%)$. These figures are comparable to those reported for Africa, but are higher than those reported for Europe and South East Asia [1].

Three MSW volunteers were tested positive for pharyngeal infection with NG. As this infection is unlikely to occur in low-risk patients, we concluded that our PCR technique produced false positives due to cross reaction of NG and Neisseria meningitidis. Accordingly, we excluded all MSW volunteers from our calculations 
of extragenital infection prevalence. Thus, extragenital infections with at least 1 of the 3 pathogens were found in 20 swabs $(20 / 91,21.9 \%)$ taken from 16 patients (16/81, 19.7\%), all of them asymptomatic.

The high prevalence of extragenital CT and NG infections suggests that many STIs are left undetected with current screening practices. This finding is supported by a cross-sectional study of 4402 women at risk of extragenital infection who visited an American STI clinic: the authors concluded that $30.3 \%$ of NG infections and $13.8 \%$ of CT infections would have been missed if only urogenital infections had been investigated [6]. Likewise, a US cross-sectional study of 7333 MSM visiting an STI clinic found that a third of pharyngeal and anal infections with NG would have been be missed if only urethral or urine specimens had been screened [7]. In turn, the high percentage of asymptomatic patients in our study $(72 / 81,88.9 \%)$ suggests that symptom-based urogenital screening alone can contribute to underestimating the prevalence of urogenital STIs. More generally, this screening approach can generate a false sense of security in asymptomatic patients, which can favour the progression of silent STIs towards irreversible complications [2]. This can be a major concern in low- and middle-income countries, which are often home to highrisk sexually active populations.

Screening for urogenital and extragenital MG raises its own set of issues, as the overprescription of azithromycin increases antimicrobial resistance in patients treated for this infection [8]. In Reunion Island, the prevalence of MG-CT co-infections is high (OR 4,62, $p=0.02)$ and several risk factors for $\mathrm{CT}$ infection have been identified, including first intercourse between ages 11 and $14(p=$ $0.02)$, lack of previous screening $(p=0.023)$, and partner infidelity $(p=0.012)$. In view of these findings, our research team argued elsewhere that routine screening for MG in poorly adherent, high-risk populations living in regions with low antimicrobial resistance may help limit the spread of MG, thereby preventing irreversible complications, especially in women (Torregrossa E, Zemali N, Gerardin P, Manaquin R, Foucher A, Jaubert J, Picot S, Poubeau P, Camuset G, Bertolotti A: Prevalence, risk factors, and symptomatology of Mycoplasma genitalium infection in Reunion Island: A cross-sectional study, submitted) (Duval C, Anthony N, Thore-Dupont E, Jaubert J, Camuset G, Von Theobald P, Franco JM, Poubeau P, Bruneau L, Bertolotti A: Prevalence and risk factor of Chlamydia trachomatis infection among women consulting sexually transmitted infection centre in La Reunion: A cross-sectional study, submitted).

\section{Conclusion}

To conclude, health care providers should be made aware of the high prevalence of extragenital CT and NG infections and urogenital and extragenital MG infections in sexually active populations. Screening practices should be updated as follows: multisite CT and NG screening should be routinely performed in patients at risk of extragenital infection, and multisite MG screening should be routinely performed in poorly-adherent, high-risk populations living in regions with low antimicrobial resistance [9]. This screening strategy may help mitigate the transmission of STIs, including in lowincome countries, which are often home to high-risk populations.

\section{Supplementary Information}

The online version contains supplementary material available at https://doi. org/10.1186/s12879-021-05801-9.

\section{Additional file 1.}

\section{Abbreviations}

STI: Sexually transmitted Infection; CT: Chlamydia trachomatis; NG: Neisseria gonorrhoeae; MG: Mycoplasma genitalium; MSM: Men who have sex with men; MSW: Men who have sex with women; PCR: Polymerase chain reaction; SD: Standard deviation; 95\% Cl: 95\% Confidence interval

\section{Acknowledgments}

We would like to thank all members of the STI team (nurses, secretaries, students) as well as E. Asgarali, A. Foucher, C. Levin, F. Andry, S. Picot, and A. Michault. We are also grateful to our copy editor Arianne Dorval.

\section{Authors' contributions}

$A B, G C$, and PG conceptualized and designed the study; AC, AB, YK, RM, CSP, $\mathrm{J}$, and NZ participated in the acquisition, analysis, and interpretation of data; $A C$ and $A B$ drafted the initial manuscript; GC, PG, PP, YK, CSP, and JJ critically reviewed the manuscript. All authors read and approved the final manuscript.

\section{Funding}

Not applicable.

Availability of data and materials

The data used during the study are available from the corresponding author.

Ethics approval and consent to participate

This study was approved by the Commission Nationale Informatique et Libertés (CNIL).

Oral informed consent was obtained from all participants and written informed consent was obtained from a parent or guardian for participants under 18 years old. The ethical character of oral consent alone for this study on totally anonymous collected data was approved by the Scientific

Committee for research of the CHU Réunion.

Consent for publication

Not applicable.

\section{Competing interests}

The authors declare that they have no competing interests.

\section{Author details}

${ }^{1} \mathrm{CHU}$ Réunion, Service des Maladies Infectieuses - Dermatologie, Saint Pierre, La Réunion, France. ${ }^{2} \mathrm{CHU}$ Réunion, Laboratoire de microbiologie, Saint Pierre, La Réunion, France. ${ }^{3}$ Inserm CIC1410, CHU Réunion, Saint Pierre, La Réunion, France. 
Received: 21 October 2020 Accepted: 13 January 2021

Published online: 21 January 2021

\section{References}

1. Rowley J, Vander Hoorn S, Korenromp E, et al. Chlamydia, gonorrhoea, trichomoniasis and syphilis: global prevalence and incidence estimates, 2016. Bull World Health Organ. 2019;97:548-62.

2. Unemo M, Bradshaw CS, Hocking JS, et al. Sexually transmitted infections: challenges ahead. Lancet Infect Dis. 2017;17:235-79.

3. CDC. Screening Recommendations and Considerations Referenced in Treatment Guidelines and Original Sources. 2015. Available from: https:// www.cdc.gov/std/tg2015/screening-recommendations.htm.

4. Soni S, Horner P, Rayment M, et al. British Association for Sexual Health and HIV national guideline for the management of infection with mycoplasma genitalium (2018). Int J STD AIDS. 2019;30:938-50.

5. Keenan $\mathrm{M}$, Thomas $\mathrm{P}$, Cotler $\mathrm{K}$. Increasing sexually transmitted infection detection through screening at Extragenital sites. J Nurse Pract. 2020;16:2730

6. Trebach JD, Chaulk CP, Page KR, et al. Neisseria gonorrhoeae and chlamydia trachomatis among women reporting Extragenital exposures. Sex Transm Dis. 2015;42:233-9.

7. Gunn RA, O'Brien CJ, Lee MA, et al. Gonorrhea screening among men who have sex with men: value of multiple anatomic site testing, San Diego, California, 1997-2003. Sex Transm Dis. 2008;35:845-8.

8. Lau A, Bradshaw CS, Lewis D, et al. The efficacy of azithromycin for the treatment of genital mycoplasma genitalium: a systematic review and metaanalysis. Clin Infect Dis. 2015;61:1389-99.

9. Van Liere GAFS, Hoebe CJPA, Niekamp A-M, et al. Standard symptom- and sexual history-based testing misses Anorectal chlamydia trachomatis and Neisseria gonorrhoeae infections in swingers and men who have sex with men. Sex Transm Dis. 2013:40:285-9.

\section{Publisher's Note}

Springer Nature remains neutral with regard to jurisdictional claims in published maps and institutional affiliations.

Ready to submit your research? Choose BMC and benefit from:

- fast, convenient online submission

- thorough peer review by experienced researchers in your field

- rapid publication on acceptance

- support for research data, including large and complex data types

- gold Open Access which fosters wider collaboration and increased citations

- maximum visibility for your research: over $100 \mathrm{M}$ website views per year

At BMC, research is always in progress.

Learn more biomedcentral.com/submissions 